\title{
"RACIOCINAR COM RECTIDÃO": QUESTÕES DA "FILOSOFIA DA IGREJA” DE JOSÉ SORIANO DE SOUZA (1871)
}

\section{"RATIOTINATE WITH JUSTICE": QUESTIONS OF "PHILOSOPHY OF CHURCH” TO JOSÉ SORIANO DE SOUZA (1871)}

\author{
Anderson Santos ${ }^{1}$ \\ Cristiano Ferronato ${ }^{2}$ \\ Ester Fraga Vilâs-Boas Carvalho do Nascimento ${ }^{3}$
}

\begin{abstract}
Resumo: no presente trabalho buscamos apresentar alguns aspectos da filosofia tradicional ou da igreja, apresentada por José Soriano de Souza em seu compêndio de filosofia, Lições de Philosophia Elementar Racional e Moral. No Brasil em meados do século XIX as questões religiosas vieram a desenvolver o interesse pela chamada filosofia da igreja, da qual se destacou como "filósofo católico" José Soriano de Souza (1833-1895). Egresso do Lyceu Provincial da Parahyba do Norte, José Soriano de Souza se tornou lente catedrática da Faculdade de Direito de Olinda, criada por Decreto Imperial, em 11 de agosto de 1827. Formou-se em Medicina, pela Faculdade de Medicina do Rio de Janeiro (1860), em 1866 recebeu o título de Honoris Causa ao concluir o curso de Filosofia na Universidade de Louvain, na Bélgica. Em 1871 na cidade do Recife o compêndio Lições de Philosophia Elementar Racional e Moral foi publicado pela Livraria Acadêmica de João Walfredo de Medeiros e adotado como manual de ensino de filosofia do Gymnasio Provincial Pernambucano, instituição a qual, o autor ocupava a cadeira de Filosofia.
\end{abstract}

Palavras-chave: Compêndio. Filosofia. José Soriano de Souza. Ensino secundário.

Abstract: in this task we search present some aspect of tradicional philosophy or church, introduced by José Soriano de Souza in your compendium philosophy, Lições de Philosophia Elementar Racional e Moral. In Brazil in the mid-nineteenth century the religious issues they came to develop the concern by so-called philosophy of church, about which stood out as "catholic philosopher" José Soriano de Souza (1833-1895). Egress of Lyceu Provincial da Parahyba do Norte, José Soriano de Souza become lens university professor in Law School of Olinda, created by Imperial Decree on august $11^{\text {th }}, 1827$. He graduated in Medicine, from Faculdade de Medicina do Rio de Janeiro (1860), in 1866 received the title of Honoris Causa to complete the course in philosophy at the University of Louvain in Belgium. In 1827 in Recife the compendium Lições de Philosophia Elementar Racional e Moral was published by the Academic Bookstore of João Walfredo de Medeiros and adopted as teaching philosophy manual to Gymnasio Provincial Pernambucano, institution about which, the writer was professor in subjects philosophy.

Key words: Compendium. Philosophy. José Soriano de Souza. Secondary teaching.

\section{Introdução}

A natureza de uma cousa se declara definindo-a, como logo sabereis; por tanto, para que conheçamos a natureza da Philosophia, preciso é defini-la. O que é pois a Philosophia? São innumeraveis as definições que lhe hão dado os

\footnotetext{
${ }^{1}$ Licenciado em História, e mestrando em Educação no Programa de Pós-Graduação em Educação da Universidade Tiradentes (Unit) - Sergipe. E-mail: andersonii@ hotmail.com

${ }^{2}$ Doutor em Educação pela Universidade Federal da Paraíba-UFPB, professor do Programa de Pós-Graduação em Educação da Universidade Tiradentes (Unit) - Sergipe. E-mail: cristianoferronato@gmail.com

${ }^{3}$ Doutora em Educação pela Pontifícia Universidade Católica de São Paulo (2005). Mestre em Educação pela Universidade Federal de Sergipe (2000), professora do Programa de Pós-Graduação em Educação da Universidade Tiradentes (Unit)-Sergipe.
} 


\section{Notandum 42 set-dez 2016 - CEMOrOC - Feusp / IJI-Univ. do Porto DOI: http://dx.doi.org/10.4025/notandum.42.3}

autores antigos, e modernos. Uns tomão por seu objecto o que lhe não pertence, outros não abrangera esse objecto em toda sua extensão real. D'ahi a grande diversidade das definições, e bem assim o desapreço em que alguns tem a Philosophia, pois não falta quem conclua dessa discrepância que não existe a cousa que a palavra é destinada a significar (SOUZA, 1871, p. 18).

Iniciamos este texto com a definição de Filosofia de José Soriano de Souza, no seu compêndio "Lições de Philosophia Elementar Racional e Moral", publicado em 187, pela Livraria Acadêmica de João Walfredo de Medeiros, em Recife. O professor, médico e filósofo José Soriano de Souza nasceu em 15 de setembro de 1833 na Cidade da Paraíba, nome com o qual era designada a capital daquela Província e destinou a maior parte da sua vida às atividades intelectuais e públicas. Formou-se em Medicina em 1860, pela Faculdade de Medicina do Rio de Janeiro ${ }^{4}$, e em Filosofia, pela Universidade de Louvain ${ }^{5}$, na Bélgica em 1866. Os estudos secundários foram realizados no Lyceu Provincial da Parahyba do Norte ${ }^{6}$, junto a seus dois irmãos, Braz Florentino Henrique de Souza ${ }^{7}$ (1825-1870) e Tarquínio Bráulio de Souza ${ }^{8}$ (18291894).

Soriano de Souza, como era chamado, tornou-se lente catedrático ${ }^{9}$ da Faculdade de Direito de Olinda ${ }^{10}$, onde lecionou Direito Público e Constitucional, além de Direito Natural e Direito Romano. Em 1867, em movimentado concurso para a Cadeira de Filosofia do Gymnásio Provincial Pernambucano, conquistou a cátedra da cadeira de filosofia do então ginásio, tendo como principal concorrente o também filósofo Tobias Barreto ${ }^{11}$ (1839-1889).

Além de professor e filósofo Soriano de Souza teve ainda uma grande atuação nos jornais católicos da Cidade do Recife atuando como redator e jornalista em periódicos como: O Cathólico, (1872), A Esperança (1864) e A União (1873). Outro campo de atuação foi na

\footnotetext{
${ }^{4}$ Fundada em 5 de novembro de 1808 pelo príncipe regente D. João, por Carta Régia, a Faculdade de Medicina da Universidade Federal do Rio de Janeiro, teve inicialmente o nome de Escola de Anatomia, Medicina e Cirurgia, e funcionava Hospital Militar do Morro do Castelo.

${ }^{5}$ A Universidade Católica de Louvain era a mais antiga, a maior e a mais proeminente universidade da Bélgica. Fundada em 1425, a universidade desmembrou-se em outras duas no ano de 1968: a Katholieke Universiteit Leuven, de fala holandesa, e a Université Catholique de Louvain, de fala francesa.

${ }^{6}$ Sobre esta instituição, conferir o estudo de Cristiano Ferronato (2014) Das aulas avulsas ao Lyceu Provincial As primeiras configurações da instrução secundária na província da Parahyba do Norte (1836-1884).

${ }^{7}$ Nasceu na Província da Paraíba em 1825, iniciou seus estudos na Faculdade de Direito do Recife em 1846, concluiu em 1850 e, já no ano seguinte conquistou seu título de doutor. Em 1855 foi nomeado professor desta mesma Faculdade, onde ocupou a cadeira de Direito Criminal. Faleceu em 1870, aos 45 anos de idade na Província do maranhão, onde um ano ates havia sido nomeado presidente.

${ }^{8}$ Nasceu em 1829 no Rio Grande do Norte. Em 1857, bacharelou-se em Direito pela faculdade de Direito do Recife, obteve seu título de doutor em 1859 e, já no ano seguinte ingressou no corpo docente desta instituição como professor substituto. Ocupou a cadeira do Direito Eclesiástico da Faculdade de Direito do Recife e, ainda foi professor de filosofia do Ateneu de Natal e, da Escola Naval do Rio de Janeiro onde veio a falecer em 29 de agosto de 1894.

9 A expressão Lente muito utilizado no sistema educacional do século XIX é sinônimo de Professor. Para a expressão Lente Catedrática devemos entendê-la como professor de uma disciplina/curso específico. Os Lentes Catedráticos tinham tempo de serviço preestabelecido e, após o término de suas atividade era nomeado um Lente Substituto para o curso/disciplina.

${ }^{10}$ Em 11 de agosto de 1827 por meio de Carta de lei sancionada por D. Pedro I foram fundadas as duas Faculdades de cursos jurídicos do Império, em Olinda e São Paulo.

11 Tobias Barreto de Menezes nasceu no dia 7 de junho de 1839 na Vila de Campos do Rio Real, atualmente a cidade chama-se Tobias Barreto. Após não ter se adaptado no seminário na Bahia em 1861, regressou para a Vila de Campos para em 1863 mudar-se para a cidade do Recife e iniciar seus estudos na Faculdade de Direito do Recife onde tornou-se membro do movimento intelectual, poético, crítico, filosófico e jurídico, conhecido como Escola do Recife. Foi lente desta mesma faculdade, além de ser Patrono da cadeira ${ }^{\circ} 38$ da Academia Brasileira de Letras. Faleceu em 26 de junho de 1889 na cidade do Recife.
} 
política, como deputado na Assembleia Provincial pelo Estado de Pernambuco entre os anos de 1886 a 1889. Com a implantação da República, conforme Campos (1998, p. 46) "participou da comissão, que elaborou o projeto de constituição do Estado de Pernambuco, tendo sido, outrossim, representante daquele Estado no Congresso Constituinte".

No entanto o que nos interessa neste trabalho foi sua atuação no campo da Filosofia onde teve grande influência no período aqui estudado, dentre suas mais significativas obras que interessam a este campo do saber, podemos apontar as seguintes: Compêndio de Filosofia, Ordenado Segundo os Princípios e Métodos de São Tomás de Aquino (Recife - 1867), Lições de Philosophia Elementar Racional e Moral (Recife - 1871), Princípios Sociais e Políticos de Santo Agostinho (Recife - 1866), Princípios Sociais e Políticos de São Tomás de Aquino (Recife - 1866), Elementos de Filosofia do Direito (Recife - 1880), Considerações sobre a Igreja e o Estado, sob o ponto de vista Jurídico, Filosófico e Religioso (Recife - 1874), Princípios Gerais de Direito Público e Constitucional (Recife - 1893).

Dito isto, importa aqui sinalizar que nossa preocupação neste texto foi analisar a atuação de Soriano de Souza no campo do ensino de Filosofia a partir da apresentação de alguns aspectos da filosofia tradicional ou da Igreja, presentes no compêndio de ensino de filosofia, Lições de Philosophia Elementar Racional e Moral, (Recife - 1871).

No que se refere à temática da produção e utilização dos manuais escolares no Brasil dos Oitocentos Galvão e Batista (2009), destacam que estes materiais deveriam dispor de uma boa organização, apresentando uma sequência lógica e, é claro não ser confuso. Ainda teriam que ser metodologicamente planejados, pois isso garantiria o uso adequado no espaço escolar e, sobretudo, a sua aprovação. Católico fervoroso, defensor da escolástica aquinense, em seu compêndio de filosofia, percebemos que as características destacadas pelos pesquisadores estão presentes no manual de Soriano de Souza.

Neste sentido temos que na segunda metade do século XIX no Brasil, mesmo com as ideias positivistas presentes nas instituições de ensino e, as críticas direcionadas aos manuais escolares utilizados nos liceus e ginásios, estes ainda permaneciam com seu embasamento de elaboração pautado na fé, segundo Schueller e Teixeira (2008, p. 565) tais obras, "mantinham fortes aproximações com os preceitos da Igreja Católica, sendo que aquela instituição influenciava na produção e na aprovação do que seria utilizado nas aulas em Liceus, Ateneus pelo país".

O compêndio de Soriano de Souza foi escrito para ser utilizado como manual de ensino de filosofia em suas aulas no Ginásio Pernambucano. Nesse sentido, temos que, o autor exercitava uma prática muito comum, entre alguns professores da segunda metade dos Oitocentos, que era a transformação das suas lições de aula e compilações de manuais, resumos e apostilas na forma dos chamados Compêndios. Tais manuais eram adotados e também serviam como incentivo à elaboração e publicação de autores nacionais. Neste sentido, Soriano de Souza está inserido neste grupo de professores-autores, uma vez que teve o seu Compêndio de filosofia adotado pelo Ginásio pernambucano como manual de ensino do curso elementar filosófico.

\section{As questões da "Filosofia da Igreja” no manual de José Soriano de Souza}

O Compêndio de José Soriano de Souza foi organizado em 560 páginas e está dividido em cinco partes, além da lição preambular, intituladas: Lógica, na primeira parte; Metaphysica Geral ou Ontologia, na segunda parte; Psychologia, na terceira parte; Theologia Natural, na quarta parte, e por fim, Ethica ou Direito Natural, na quinta e última parte. 
Consta no prefácio da obra um estudo sobre duas correntes filosóficas, uma delas a filosofia cristã e a outra a filosofia racional, ou mesmo a "representação de um embate entre o naturalismo moderno e o sobrenaturalismo clássico ou medieval" (SANTOS, 2013, p. 79). A partir dessa constatação, pode-se afirmar que o objetivo maior do autor com seu Compêndio era defender a relevância e utilização da filosofia cristã em relação à filosofia pautada na razão, como lemos a seguir.

Naturalismo e sobrenaturalismo, razão independente fé humilde, taes são portanto os termos da magna questão debatida na sociedade moderna desde que ao grito da independência religiosa do século XVI; seguio-se o da independência philosophica escrevendo logo o patriarcha da moderna philosophia na primeira página do seu codigo a razão humana ê por natureza independente. Desde então um espírito maligno e inimigo das crenças da humanidade parece querer destruir todas as cousas estabelecidas, assim na ordem politica, como na moral e intellectual (SOUZA, 1871, p. 5).

A segunda parte do Compêndio, intitulada, Metaphysica geral ou Ontologia, trata do conhecimento metafísico, que o autor divide em três partes: Ontologia, Psicologia e Teologia natural.

A divisão da metaphysica sahe da natureza de seu objecto, o qual, como já vimos, é o ente incorporeo por sua propria natureza ou por precisão do espirito, isto é, são aquelles entes que não só não existem nunca unidos á materia, como Deos e os anjos, mas tambem os que podem estar na materia como a alma humana e o ente commum. Por consequencia toda a metaphysica se divide em duas partes, uma que trata do ente commum, chama-se Ontologia ou a sciencia do ente, e outra que se occupa de Deos e das mais substancias espirituaesaqual chama-se Pneumatologia ou a sciencia dos espíritos. Esta se subdivide ordinariamente em Psycholoyia, que trata d'alma racional e Theologianutural, que trata de Deos, quanto é perceptível'ás luzes da razão natural. Deixando pois de parte os anjos, temos que a metaphysica se divide em Ontologia, Psychologia, e Theologia natural (SOUZA, 1871, p. 122).

A essência da alma humana, suas qualidades e a relação com o corpo, são os conceitos que direcionam a discussão contida na parte dedicada por Soriano de Souza à Psicologia. É importante ressaltar que este é o capítulo de maior extensão da obra. Nesta parte segundo Martins (2009) "o ser humano é definido como ser dotado de potência e capacidade superior aos demais". Para melhor explicar o ser humano e seus diversos vínculos com a realidade, o autor utilizou o pensamento tomista escolástico como o mais adequado referencial teóricometodológico. Como demonstrativo do conhecimento de São Tomás de Aquino, também é discutido neste item o conceito de liberdade e imortalidade da alma, como lemos a seguir.

Mas ha duas especies de espirito, o increado, que é Deos, e o creado que são os anjos, e a alma racional. [...] Para especificar o tratado do espirito humano é que commumente empregão em sentido estricto a palavra psychologia; a qual portanto se differença da pneumatologia como a especie do genero, o particular do universal. [...] Mais adequado, digo eu, porque é impossível conhecer bem a alma racional em suas operações, faculdades e propriedades 


\section{Notandum 42 set-dez 2016 - CEMOrOC - Feusp / IJI-Univ. do Porto DOI: http://dx.doi.org/10.4025/notandum.42.3}

sem attender a intima união em que naturalmente está com o corpo, e a consequente influencia reciproca que a alma exerce sobre o corpo e o corpo sobre a alma. (SOUZA 1871, p. 190, 191).

Ancorado nas afirmações escolásticas é discutido na quarta e quinta parte da obra o conhecimento da existência de Deus, sob a lente do conhecimento medieval (escolástica). "Deos é inconprehensivel ao espirito limitado do homem; esta é a verdadeira causa de não podermos dizer perfeitamente o que é Deos" (SOUZA 1871, p. 357). Em Ehtica ou Direito Natural, são discutidas as ações humanas na perspectiva individual e social. Diante disso, Soriano de Souza destaca que "não póde nesta vida haver nada tão excellente e util, como saber o homem dirigir suas acções rectamente aos seus áividos fins; só assim póde elle chegar ao seu destino" (1871, p. 413), neste caso a felicidade.

Elaborado a partir de padrões Aquinenses, o compêndio de Soriano de Souza, demonstra em seu texto os aspectos da fé e, segundo alguns estudiosos do tradicionalismo do autor, que ao longo dos capítulos defende o pensamento escolástico tomista, e sua utilização nas lições das disciplinas que estava encarregado de lecionar. $\mathrm{O}$ autor utilizou o tomismo, como "uma teoria de compreensão da realidade e também como uma teoria geral do Estado Monárquico em vigor, elucidando as características do padroado adotado por D. Pedro II" (MARTINS, 2009, p. 9).

As questões que o lançam ao movimento chamado de "Filósofos da Igreja" estão presentes em seu compêndio. Importante ressaltar que, o autor elaborou seu compêndio conforme o que era aconselhado no estatuto reformado em 1772 da Universidade de Coimbra. O estatuto definiu os parâmetros sob os quais os manuais para o curso filosófico deveriam ser elaborados, definia também que era fundamental a presença dos estudos escolásticos nas lições do autor. Isso nos levou a refletir que não seria incomum não nos depararmos com esses preceitos oriundos da escrita de Soriano de Souza, além do mais, o ocupante da cadeira de Filosofia do Ginásio Pernambucano era egresso da Universidade Católica de Louvain na Bélgica, tendo nesta instituição obtido o seu título de doutor em filosofia.

Diante disso nos lembra Choppin (2009) que foi através de textos, semelhante ao compêndio aqui analisado, cujo conteúdo remetia à religião, que se processaram as primeiras aprendizagens da cristandade. E mesmo com as iniciativas do poder público para a organização do ensino popular, um manual específico para uma determinada disciplina, o catecismo ainda era colocado nas mãos dos alunos e, este também era observado como manual. Dentro desta perspectiva ainda aponta Choppin $(2009$, p. 46) que os "primeiros alfabetos e livros de leitura estão compostos de expressões ou de curtas passagens emprestadas da Bíblia”. E mais adiante, cabe lembrar que mesmo nos manuais que não apresentam nenhum conteúdo religioso, é possível nos depararmos com essas expressões.

A questão não é portanto simples, pela definição de edição religiosa não é mais evidente. Yvan Cloutier assinala que ao lado da definição que se dá habitualmente, centrada sobre os conteúdos (o conjunto dos impressos tem nos títulos uma conotação religiosa explícita: espiritualidade, Bíblia, moral, teologia, livro de oração, etc.), podemos pensar hoje uma outra, mais ampla, que se apoiando sobre a finalidade do editor inclui todos os títulos produzidos num viés evangelizador, sem olhar a conotação explícita do conteúdo (CHOPPIN, 2009, p. 48). 


\title{
Notandum 42 set-dez 2016 - CEMOrOC - Feusp / IJI-Univ. do Porto DOI: http://dx.doi.org/10.4025/notandum.42.3
}

Acerca disso podemos refletir então que, além da possibilidade de existência da permeabilidade entre edição religiosa e edição escolar, ainda pode haver a mesma relação entre edição religiosa e edição para a juventude. Aquela frequentando o ensino primário em preparação para o ensino secundário e, esta segunda, se preparando para as instituições de ensino superior.

De acordo com França (1978) para a compreensão das problemáticas fundamentais, tanto do nível teórico, quanto nível prático, sobreposto ao longo da história, segundo a tradicional concepção católica, só era possível, seguindo uma filosofia única e certa. Partindo de um núcleo de verdades inexoráveis, constituindo a base ou o seu ponto de partida para as investigações filosóficas, pois a razão orienta-se seguramente em direção da verdade. "Haja vista que, cumpre-lhe, pois, saber distinguir os desvios multiformes do caminho único e certo. Cumpre-lhe discernir o sistema verdadeiro dos errôneos. Cumpre-lhe reconhecer, entre as filosofias, a Filosofia" (FRANÇA, 1978, p. 328).

Soriano de Souza procurou dirigir suas lições expostas no compêndio por esse caminho. Reconhecendo dentro do campo filosófico sua filosofia, aquela preocupada em exaltar a sua religião. Assim o fizera no diálogo entre as filosofias moderna e tradicional não lançando uma a frente da outra, mas tratando-as como provenientes do mesmo ser e, sendo assim, havendo a possibilidade de trabalhar ambas em harmonia.

\begin{abstract}
Sim, de certo a razão humana e a religião, a filosofia e a revelação ambas procedem da razão divina [...] mas quão desarrazoada seja aquella igualdade fraternal, facilmente se colhe de ser a religião pensamento divino, verdade eterna, invariavel e perpetua, e a philosophia pensamento humano, e como tal variável e sujeito a paixões e erros. O pensamento humano, instrumento da philosophia, e a fé instrumento da religião são dons de Deos; mas nem por isto havemos de pôr a religião no mesmo pé de igualdade que a philosophia. Se o terem ambas sahido das dadivosas mãos de Deos fosse razão de as declararmos irmãs [...] eis que por ahi iria a presumida fraternidade parar no abominável pantheismo! Não, philosophia não póde ter o mesmo poder que a religião; aquella vem do homem e é obra de seu espirito; esta vem de Deos, e é obra de sua sabedoria e de seu amor. Não diremos que a filosofia é escrava da religião, porque aquella palavra é odiosa e violenta, mas porque não apellida-la serva affectuosa e humilde, discípula docil e obediente da religião (SOUZA, 1871, p. 8).
\end{abstract}

Segundo Bittencourt, "na segunda metade do século XIX mesmo com a projeção de autores da religião protestante, não significou a ausência de religiosos católicos na tarefa a que vinham se dedicando há tantos anos" (2004, p. 487). Vale lembrar que no decorrer daquele século ocorreu a retomada das atividades educacionais pelos jesuítas, e estes como agentes da educação, "também contribuíram com a elaboração de manuais de ensino, como o padre Rafael Maria Galanti, professor no Colégio Anchieta em Nova Friburgo" (Bittencourt, 2004, p. 487).

Já na segunda metade do século XIX, personalidades de posição religiosa continuaram a contribuir com a escrita de manuais de ensino e, além disso, ainda eram presença frequente como lentes dos liceus e ginásios do Império, locais onde o ensino das cadeiras de cursos específicos ocorria com a utilização daqueles manuais fundamentados no tomismo.

Esse predomínio da filosofia tomista cultivada nas instituições de ensino secundário ocorria porque recrutavam-se intelectuais formados em filosofia 


\section{Notandum 42 set-dez 2016 - CEMOrOC - Feusp / IJI-Univ. do Porto DOI: http://dx.doi.org/10.4025/notandum.42.3}

nos Seminários, e muitos iam estudar em faculdades católicas europeias, como em Louvain, na Bélgica" (MARTINS, 1985, p. 43 ).

Convêm aqui ressaltar ainda duas questões importantes que exemplificam essa prática, o primeiro, o concurso em 1867 que colocou José Soriano de Souza e Tobias Barreto como concorrentes a cadeira de filosofia do Ginásio Pernambucano e, o segundo, outro concurso, este em 1875, para a cadeira de filosofia do Colégio das Artes de Recife, onde foi colocado Silvio Romero ${ }^{12}$ (1851-1914), seguidor das chamadas ideias evolucionistas, frente a, Antonio Luís de Mello Vieira ${ }^{13}$, identificado com o tomismo.

Em alusão ao fim religioso que as lições filosóficas contidas no compêndio podem proporcionar aos jovens estudantes, Soriano de Souza recomenda que estes tenham sempre presente em suas reflexões a religião, pois esta segundo o autor se não cria talentos, devolve e tempera os que a natureza dá. Em se tratando da relação homem e religião, só a segunda compete à última palavra, assim destaca Soriano de Souza. A última palavra sobre o princípio e o fim do homem, sendo esta definida pela autor como a

[...] questão maxima da philosophia, assim como sobre os meios de attingir a aquelle fim; e a philosophia que não quizer ser inimiga do homem, deve esforçar-se por conduzi-lo direitamente ao seu destino. Por esse modo vem a philosophia [...] a não ter verdadeiramente outro fim que a religião; Summus philosophise finis religio (SOUZA, 1871, p. 18).

Percebe-se então que, segundo Soriano de Souza, a filosofia seria uma ciência do espírito, que conduzia o homem a felicidade divina. Pois tendo o homem uma propensão natural para amar e honrar a Deus, de quem recebe tudo o que é, e, o que tem inclusive a filosofia, pois esta, assim como a razão humana, conforme assinala José Soriano (1871) é fruto das dadivosas mãos de Deus.

Tendo discutido nas partes anteriores sobre a alma humana, suas faculdades e operações, bem como sobre o modo de dirigir convenientemente os jovens estudantes no caminho da verdade (a razão pautada na fé), na quarta parte do compêndio, aquela intitulada Theologia Natural, o autor discorre sobre o próprio Deus, criador da alma, sua essência, existência, onipotência, baseando-se principalmente nos estudos de Aristóteles, S. Thomaz de Aquino, Descartes e Leibnitz.

"Mas, o que é Deos"? (SOUZA, 1871, p. 357). Indaga o autor nos início das suas lições. Em pronta resposta aos alunos, já esclarece que Deus é incompreensível ao espírito limitado do homem, sendo esta a principal causa de não ser possível dizer perfeitamente o que é Deus. "Se o não podemos conhecer deste modo, digo, certamente o concebemos. Se não temos delle um conhecimento perfeito, o conhecemos sufficientemente para saber que Elle é [...] o ente de si, infinitamente perfeito, e causa primeira de todas as cousas" (SOUZA, 1871, p. 358).

Pautado no pensamento de Aristóteles, onde para o estudo de qualquer objeto, poderia naturalmente basear-se em três questões básicas: $1^{\mathrm{a}}$ - essa coisa existe? $2^{\mathrm{a}}-\mathrm{o}$ que é ela? $3^{\mathrm{a}}-$

\footnotetext{
${ }^{12}$ Silvio Romero foi professor, político, crítico literário e filósofo. Em 1873 concluiu o curso de Ciências Jurídicas pela Faculdade de Direito no Recife. Após prestar concurso em 1879 passou a ocupar a cadeira de Filosofia do Imperial Colégio de D. Pedro II no Rio de Janeiro.

${ }^{13}$ Antonio Luís de Mello Vieira, tomista, professor de filosofia do Curso anexo da Faculdade de Direito do Recife, autor da tese Da interpretação filosófica na evolução dos fatos históricos.
} 
como é ela? "A primeira respondemos provando a existencia da dita cousa; a segunda explicando a sua essencia ou natureza, a terceira declarando as suas qualidades ou atributos" (SOUZA, 1871, p. 359). Aplicando esse pensamento ao objeto de estudo da quarta parte do compêndio, neste caso Deus e sua existência, tratou Soriano de Souza, de somar aos três questionamentos anteriores mais duas questões, $1^{\mathrm{a}}$ - se a existência de Deus é coisa demonstrável, e $2^{\mathrm{a}}$ - se dessa existência podemos dar demonstrações verdadeiramente a priori. Dialogando com vertentes a favor ou não desses conceitos que priorizam os estudos da existência ou não de Deus, o autor atribui para si, bem como para a finalidade da disciplina Teologia Natural, exposta na quarta parte do seu compêndio que para provar a existência de Deus baseou-se no fundamento que a maioria dos filósofos preocupados com essa dinâmica se basearam. Este princípio para aqueles que creem na sua existência deveria orientar-se na crença de um Deus invisível, mas conhecido por seus efeitos visíveis, segundo Soriano de Souza (1871).

Pensando tal posicionamento do autor do compêndio aqui analisado em relação com as finalidades das disciplinas para com os alunos, lembra-nos Chervel (1990, p. 192) "que os mestres faz os alunos adquiri-las apenas depois de as terem decomposto metodicamente em pequenos pedaços que eles assimilam um após o outro". Que significa para o autor a alternância ou renovação dos métodos, onde através da exposição, dos comentários e, da interrogação, surge nas escolas um ensino mais qualificado.

Ademais, nos lembra Galvão e Batista (2003) que os textos e impressos utilizados na instrução dispõe de algumas particularidades. Com efeito, em maior e menor grau, já no século XIX, esses textos eram objetos de controle do estado e ainda atuavam, com excelência, na propaganda religiosa. Carregando em si essas características são de fato os livros, manuais de ensino, compêndios, reprodutores e condicionadores de um

[...] modo de organização da cultura escolar, concepções pedagógicas, maneiras de escolarizar saberes. Eles são, portanto, realmente, objetos por meio dos quais se pode buscar construir a história dos modos de conceber, pelo estado, a formação ideológica da criança, bem como dos processos pelos quais a escola constrói sua cultura, seus saberes, suas práticas (BATISTA e GALVÃO, 2003, p. 166).

Não é nossa intenção neste breve ensaio afirmar que com seu compêndio Soriano de Souza pretendia lançar seus jovens alunos ao credo da igreja, pelo contrário, como historiadores trabalhamos com os vestígios deixados pelo homem em determinado espaço e tempo. Segundo Chervel (1990) em determinada época da história, a sociedade, a família e, a religião, sentiram a necessidade de delegar certas tarefas educacionais a uma instituição especializada. Ademais o autor ainda afirma que "tais instituições devem sua origem a essas demandas" (1990, p. 187).

Em sua obra o ocupante da cadeira de filosofia do Ginásio Pernambucano orienta os seus alunos a dirigir os atos da razão para a aquisição da verdade. Refletindo sobre esse pensamento do filosofo, voltamos a olhar para a imagem que as instituições de ensino da segunda metade do século XIX, queriam para seus jovens estudantes. Os bons costumes, as conveniências, a exigências da retórica e, sobretudo, a religião.

Soriano ao concluir o manual o dedica literalmente ao juízo da igreja: 
Sujeito estas Lições de Philosophia ao juizo indefectível da Santa Igreja Romana, isto é, á correcção do Soberano Pontífice, Pai e Mestre infallivel de todos os christãos; e com elle digo, e tenho como verdade que é obrigação rigorosa, quer do philosopho, que deseja ser filho da Igreja, quer da mesma philosophia, não dizer nada contra o que a Igreja ensina, e retractar-se desde que Ella o adverte; e bem assim que inteiramente erronea e soberanamente injuriosa á Fé á Igreja e á sua autoridade a doutrina que ensina o contrario disto (SOUZA, 1871, p. 544).

Neste sentido a partir deste trecho retirado do manual de Soriano de Souza, temos que sendo a filosofia útil e necessária a moral, a ciência jurídica, social e econômica, esta também seria demasiadamente útil à religião, refletindo sobre os preceitos da fé, da existência de Deus, sua unidade e, outros atributos absolutos, que dela o fizeram.

Por sustentar seu pensamento filosófico em sua fé, Soriano de Souza foi muito criticado por outros intelectuais, contemporâneos seus, entre aqueles destacou-se o sergipano Tobias Barreto, autor de Ensaios e estudos de filosofia e crítica (1875); Ensaio de pré-história da literatura alemã, Filosofia e crítica e Estudos alemães (1879), considerado pela historiografia como o seu principal desafeto. Talvez por uma prática específica dos seus respectivos espaço e tempo, ou ainda por terem concorrido ao mesmo concurso, onde defenderam posicionamentos filosóficos distintos para o curso de Filosofia Racional e Moral do Ginásio Provincial Pernambucano.

No trato das ciências, Soriano de Souza não buscou discernir entre a divina e humana. Muito pelo contrário, teve a convicção de que a ciência divina não ofusca a ciência humana. Uma vez que esta última ao persistir ser guiada pela fé "é como o telescopio da intelligencia, pois allonga o seu horizonte, e faz-lhe descobrir novos astros no céo do pensamento e da verdade" (SOUZA, 1871, p. 10). Eis a filosofia escolástica ou tomística, cujo autor buscou trabalhar ao longo do seu compêndio.

\section{Considerações finais}

Para Braudel (1978, p. 22) "como a própria vida, a história se nos aparece como um espetáculo fugidio, movediço, feito do entrelaçamento de problemas inextrincavelmente misturados [...] como abordar e fragmentar essa vida complexa, para poder apreendê-la ou ao menos aprender alguma coisa nela"?

Nossa intenção em analisar alguns aspectos da filosofia tradicional ou da igreja presente no compêndio de filosofia Lições de Philosophia Elementar Racional e Moral de José Soriano de Souza, baseou-se nessa afirmação. Haja vista que os conteúdos, bem como o posicionamento filosófico encontrado na obra não eram algo fora do comum para a época. Assim como comentado anteriormente, os casos de professores egressos de faculdades católicas europeias lecionando nos ginásios brasileiros eram significativos. Isso nos permite visualizar essa postura religiosa de alguns professores, seja naqueles que elaboravam seus próprios compêndios e, também, nos que utilizavam compêndios europeus traduzidos, sobretudo franceses, para as suas lições.

Para Macedo (1997, p. 169) "ainda não se fez justiça ao empenho filosófico de Soriano". Assim, é importante que se compreenda que o plano filosofia-religião pensado por Soriano de Souza busca uma harmonia entre ambas e não um distanciamento. Não considerou 
usar o termo de que a "philosophia é escrava da religião" (SOUZA, 1871, p. 8), muito pelo contrário, julgou ser tal palavra dotada de ódio e violência, preferindo lançar a filosofia diante da religião como uma grande aliada que observa as [...] "advertencias da religião de Jesus Christo" e ouve suas "lições, e faz suas delicias em trilhar o caminho que lhe aplanarão" (SOUZA, 1871, p. 9).

José Soriano de Souza como bem demonstrou Campos (1998) foi um pensador sincero, que defendeu suas posições, com clareza e plena consciência. O embasamento teórico/filosófico ao qual conhecia e utilizou, não somente para a elaboração do compêndio aqui analisado, influenciou diretamente sua vasta obra literária, jurídica, política, filosófica e religiosa. A soma de todos esses aspectos relacionados ao intelectual tomista, professor da cadeira de filosofia do Ginásio Pernambucano lhe garante indiscutivelmente um lugar de destaque no contexto histórico cultural brasileiro dos oitocentos.

\section{REFERÊNCIAS}

BITTENCOURT, Circe Maria F. Autores e editores de compêndios e livros de leitura (18101910). Educação e Pesquisa, 30 (3), 475-491, 2004.

BRAUDEL, Fernand. Escritos sobre a história. São Paulo: Perspectiva, 1978.

CHERVEL, A. História das Disciplinas Escolares: reflexões sobre um campo de pesquisa. Teoria \& Educação, 2, 177-229, 1990.

CHOPPIN, Alain. O manual escolar: uma falsa evidência histórica. Revista História da Educação, 13 (27), 9-75, 2009.

FERRONATO. Cristiano de Jesus. Das avulsas ao Lyceu Provincial: as primeiras configurações da instrução secundária na província da Parahyba do Norte (1836-1884). Aracaju: Editora Oficial do Estado e Sergipe - EDISE; Universidade Tiradentes, 2014.

GALVAO, Ana Maria de Oliveira e BATISTA, Antônio Augusto Gomes. (2003). Manuais escolares e pesquisa em História. In: VEIGA, Cynthia Greive \& FONSECA, Thais Nívia de Lima. História e Historiografia da Educação no Brasil. Belo Horizonte: Autêntica, 2003.

GALVAO, Ana Maria de Oliveira \& BATISTA, Antônio Augusto Gomes. Livros escolares de leitura no Brasil: elementos para uma história. Campinas, SP: Mercado das Letras, 2009.

MACEDO, Ubiratan Borges de. A ideia de liberdade no século XIX: o caso brasileiro. São Paulo: Editora Expressão e Cultura, 1997.

MARTINS, Patrícia Carla de Melo. Teoria da História e Neotomismo no paradigma educacional brasileiro do século XIX. In: Simpósio Nacional de História, 2009, Fortaleza. Anais... Fortaleza: Universidade Federal do Ceará, 2009. p. 1 - 10.

SANTOS, Marcus Everson. "Para instruir o espírito e melhorar o coração": compêndios escolares de filosofia racional e moral em Sergipe no século XIX. 2013. Dissertação (Mestrado em Educação). Universidade Federal de Sergipe, Aracaju, 2013. 
SCHUELER, Alessandra Frota M. \& TEIXEIRA, Giselle Baptista. Civilizar a infância: moral em lições no livro escolar de Guilhermina de Azambuja Neves (Corte imperial, 1883).

Revista de Educação Pública, 17(35), 563-577, 2008.

SOUZA, José Soriano. Lições de Philosophia Elementar Racional e Moral. Recife: Livraria Acadêmica de João Walfredo de Medeiros, 1871. 